Study Report 2009-05

\title{
Noncommissioned Officer Education System (NCOES): Considerations for Testing-out and Awarding Equivalent Credit
}

\author{
Richard L. Wampler and Paul N. Blankenbeckler \\ Northrop Grumman Corporation
}

\author{
ARI - Ft Benning Research Unit \\ Scott E. Graham, Chief
}

U.S. Army Research Institute for the Behavioral and Social Sciences

2511 Jefferson Davis Highway, Arlington, Virginia 22202-3926

November 2008

Army Project Number

665803D730
Personnel and Training

Analysis Activities

Approved for public release; distribution is unlimited. 